\title{
Esophagus and Esophagogastric Junction Cancer cM0 TNM Finding v7
}

National Cancer Institute

\section{Source}

National Cancer Institute. Esophagus and Esophagogastric Junction Cancer cMO TNM

Finding v7. NCI Thesaurus. Code C89747.

Esophagus and esophagogastric junction cancer without evidence of distant metastasis.

(from AJCC 7th Ed.) 